\title{
Texture Development and Material Flow Behavior During Refill Friction Stir Spot Welding of AlMgSc
}

\author{
JUNJUN SHEN, SARA B.M. LAGE, UCEU F.H. SUHUDDIN, \\ CLAUDEMIRO BOLFARINI, and JORGE F. DOS SANTOS
}

The microstructural evolution during refill friction stir spot welding of an AlMgSc alloy was
studied. The primary texture that developed in all regions, with the exception of the weld center,
was determined to be $\langle 110\rangle$ fibers and interpreted as a simple shear texture with the $\langle 110\rangle$
direction aligned with the shear direction. The material flow is mainly driven by two
components: the simple shear acting on the horizontal plane causing an inward-directed spiral
flow and the extrusion acting on the vertical plane causing an upward-directed or down-
ward-directed flow. Under such a complex material flow, the weld center, which is subjected to
minimal local strain, is the least recrystallized. In addition to the geometric effects of strain and
grain subdivision, thermally activated high-angle grain boundary migration, particularly
continuous dynamic recrystallization, drives the formation of refined grains in the stirred zone.

https://doi.org/10.1007/s11661-017-4381-6

(c) The Minerals, Metals \& Materials Society and ASM International 2017

\section{INTRODUCTION}

Aluminum alloys have been increasingly used in the automotive industry in an attempt to reduce vehicle weight and improve fuel economy. ${ }^{[1,2]}$ The welding technique for assembling aluminum sheets is one of the key technology drivers for the realization of such objectives. $^{[3]}$ Thus, friction stir spot welding (FSSW), a variant of friction stir welding (FSW), is considered an alternative welding technique to replace the widely used resistance spot welding and other similar processes due to its advantages such as less energy consumption, longer tool life, and no use of consumables. ${ }^{[1,2,4]}$ Conventional FSSW leaves a keyhole behind, which may compromise the weld integrity. To avoid this, a refill process was integrated into FSSW by Helmholtz-Zentrum Geesthacht ${ }^{[5]}$ (HZG, former GKSS), which was named refill friction stir spot welding (refill FSSW) or friction spot welding (FSpW) internally in HZG and Germany.

JUNJUN SHEN, UCEU F.H. SUHUDDIN, and JORGE F. DOS SANTOS are with the Department of Solid-State Joining Processes, Materials Mechanics, Institute of Materials Research, HelmholtzZentrum Geesthacht, Max-Planck-Str. 1, 21502, Geesthacht, Germany. Contact e-mail: junjun.shen@hzg.de SARA B.M. LAGE is with the Department of Solid-State Joining Processes, Materials Mechanics, Institute of Materials Research and also with the Department of Materials Engineering, Federal University of São Carlos, Rod. Washington Luiz km. 235, 13565-905, São Carlos, Brazil. CLAUDEMIRO BOLFARINI is with the Department of Materials Engineering, Federal University of São Carlos.

Manuscript submitted November 30, 2016.

Article published online October 24, 2017
The basic concept of refill FSSW via sleeve plunging is intuitive, as shown in Figure 1. In the beginning, the clamping ring holds the materials against the backing anvil. Then, the sleeve rotates and plunges downward into the material to the desired depth, while the rotating pin simultaneously moves upward. In the meantime, a softened plasticized material rod and a local softened keyhole are formed by frictional heating and plastic deformation. After a certain time (not mandatory), the rotating sleeve and pin return to their initial positions, refilling the keyhole with the softened rod, resulting in a keyhole-free joint. Unlike FSW, where a traversing motion is involved in addition to the rotating motion, refill FSSW is similar to a special torsion process where the length of the rod (or shaft) varies all the time. At any moment, the central axis of the rod is subjected to minimal shear strain and the edge to the maximal. In general, the material undergoes intense plastic deformation at elevated temperatures, similar to FSW, resulting in the generation of fine and equiaxed recrystallized grains. Such a fine microstructure is usually favorable for joint mechanical properties.

Since its invention, refill FSSW has been used for joining similar metals or materials ${ }^{[6-10]}$ as well as joining dissimilar materials. ${ }^{[11-14]}$ HZG proved that refill FSSW creates joints with superior mechanical properties to similar processes. The underlying welding mechanisms, such as the material flow behavior, are still unclear. The material flow behavior involves the way in which the material is transferred and deposited, and thus, it is a key to understanding friction-based welding processes. For instance, material flow during FSW is driven by simple shear resulting from both the tool shoulder and 
the pin. ${ }^{[15,16]}$ However, the coexistence of shoulder-induced and pin-induced textures may decrease the integrity of the weld in subsequent performance. ${ }^{[17-19]}$ Therefore, understanding the material flow behavior is of practical importance for optimizing tool design and obtaining welds with high structural efficiencies. ${ }^{[20]}$ Furthermore, a refill FSSW process model has not yet been established. A clear understanding of the involved physical process (material flow) will be crucial. In addition, it is unknown that how the beneficial fine microstructure develops.

Therefore, in an attempt to establish a fundamental understanding of the material flow and the formation of refined grains during refill FSSW, microstructure and texture evolution in the whole weld were investigated.

\section{EXPERIMENTAL PROCEDURES AND MATERIALS}

The base metal used in this work is 1.65-mm-thick KO-8542, provided by Airbus. Its mechanical properties are shown in Table I. The welding tool consists of a clamping ring, a sleeve, and a pin that have diameters of 14.5, 9, and $6 \mathrm{~mm}$, respectively. Normal welding experiments were performed to produce representative joints using the following welding parameters: rotation speed of the sleeve and pin of $1000 \mathrm{rpm}$, maximum plunge depth of the sleeve of $1.6 \mathrm{~mm}$, plunge time of 1 second, and clamping force of $9 \mathrm{kN}$. In addition, a series of "stop action" welding experiments were carried out to produce stop-action joints to obtain more insight into the material flow. In these experiments, the welding process was terminated by pressing the emergence button during the penetrating or refilling stage at different sleeve depths, i.e., $0.5,1.0,1.5$, or $2.0 \mathrm{~mm}$, while the rotational speed, penetrating/retracting rate, and clamping force were kept constant at $1000 \mathrm{rpm}, 1$ $\mathrm{mm} / \mathrm{s}$, and $9 \mathrm{kN}$, respectively. Then, a mixture of ice and water was poured to freeze the microstructure.

The optical microscopy (OM) and electron back-scattered diffraction (EBSD) techniques were used to examine the microstructural development. Samples for OM observation that were taken from both the representative joints and the stop-action joints were sectioned through their centers, prepared by standard metallurgical procedures, and etched using a solution containing 5 $\mathrm{mL}$ of hydrofluoric acid, $10 \mathrm{~mL}$ of sulfuric acid and 185 $\mathrm{mL}$ water. The OM studies were performed using a Leica optical microscope. Two samples for EBSD analysis were sectioned from the representative joints, one through its center (on the transverse plane) and the other one $\sim 0.7 \mathrm{~mm}$ below the weld top (on the horizontal plane), and prepared by standard metallurgical procedures followed by vibration polishing. EBSD data acquisition was conducted using an FEI Quanta 650 FEG scanning electron microscope equipped with a TSL OIM EBSD system at $15 \mathrm{kV}$ under a step size of $0.15 \mu \mathrm{m}$. Each scanning area was $138 \times 138 \mu \mathrm{m}^{2}$. To eliminate spurious boundaries caused by orientation noise, a lower limit boundary misorientation cut-off of 2 deg was used. A $15 \mathrm{deg}$ criterion was employed to differentiate low-angle grain boundaries (LAGBs) from high-angle grain boundaries (HAGBs). A threshold value of grain orientation spread (GOS) of 2 deg was adopted to define the maximum intragranular misorientation cut-off angle for the fraction of recrystallized grains (ReX pct).

In this study, the experimental reference frame of refill FSSW is defined by the longitudinal direction (LD), transverse direction (TD), and normal direction (ND) as shown in Figure 2(a). Crystallographic data were obtained from several locations on the representative samples, which are illustrated as solid lines in Figure 2(a) (see also Figure 3). Column "C1" lies on the centerline of the SZ, and columns "C2" and "C3"

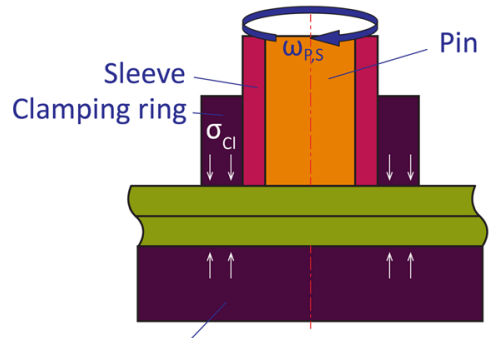

(a)

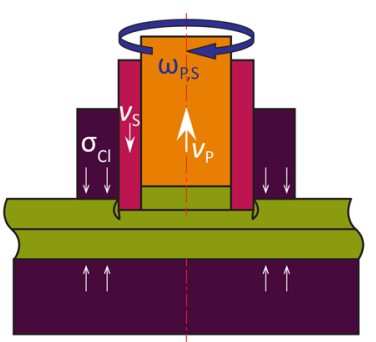

(b)

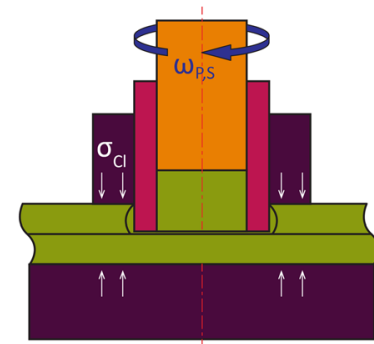

(c)

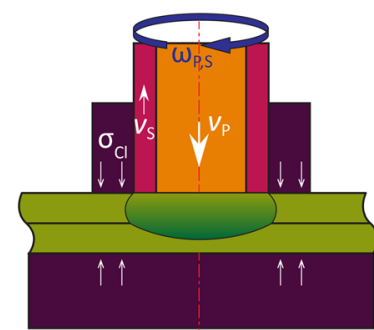

(d)

Fig. 1-Schematic diagram showing the refill FSSW process: (a) loading, (b) plunging, $(c)$ dwelling, and (d) refilling.

Table I. The Mechanical Properties of AIMgSc (KO-8542)

\begin{tabular}{lcccc}
\hline & \multicolumn{3}{c}{ Tensile Properties } & A (Percent) \\
\cline { 2 - 5 } Alloy & $\mathrm{Rp}_{0.2}(\mathrm{MPa})$ & UTS (MPa) & Microhardness (Hv) \\
\hline AlMgSc $(\mathrm{KO}-8542)$ & $330 \pm 1$ & $441 \pm 2$ & $7.13 \pm 0.75$ & $113 \pm 2$ \\
\hline
\end{tabular}




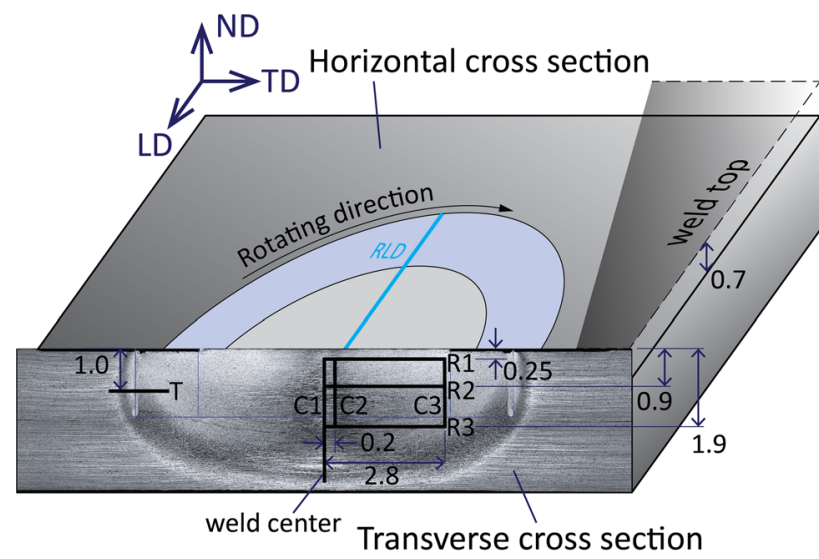

(a)

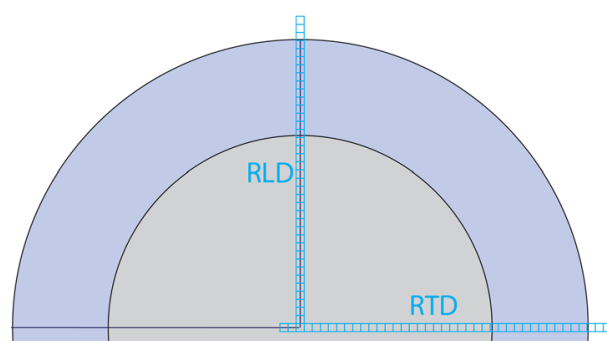

Horizontal cross section

(b)

Fig. 2-Schematic illustration of the transverse cross section and the horizontal cross section. EBSD data were obtained from the regions indicated by $(a)$ thick solid lines "T", "C1"-"C3", "R1"-"R3" on the transverse plane and $(b)$ rectangular "RLD" and "RTD" on the horizontal plane. The unit of length is $\mathrm{mm}$.

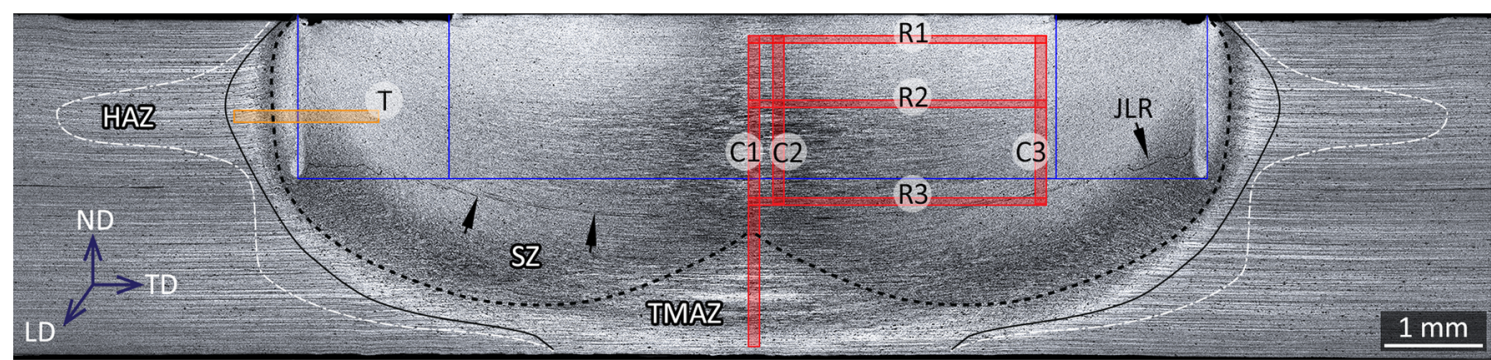

Fig. 3-Macroscopic view of a representative joint, overlaid with the sleeve (solid blue lines) and EBSD scanning routes (orange and red rectangular). The reference frame is LD-TD-ND.

are located 0.2 and $2.8 \mathrm{~mm}$ from the $\mathrm{SZ}$ center on the transverse cross section (TD-ND plane). Rows "R1", "R2", and "R3" are located $0.25,0.9$, and $1.9 \mathrm{~mm}$ from the weld top, respectively. Location " $\mathrm{R} x \mathrm{C} y$ " represents the intersection of row $\mathrm{R} x$ and column $\mathrm{C} y$; for example, $\mathrm{R} 1 \mathrm{C} 1$ is where column $\mathrm{C} 1$ and row $\mathrm{R} 1$ intersect. Column "RLD" in parallel with the LD and row "RTD" in parallel with the TD are along the radial direction on the horizontal cross section (LD-TD plane), which is located $\sim 0.7 \mathrm{~mm}$ below the weld top. These notations are used throughout the remainder of the article if no statement is given otherwise.

\section{RESULTS}

\section{A. Low-Magnification Overview of a Typical Weld}

Figure 3 represents a refill friction stir spot weld. According to the macro-/microstructural characterization of the grains and the local microhardness, three distinct zones, i.e., the stirred zone (SZ), thermomechanically affected zone (TMAZ), and heat-affected zone (HAZ), have been identified as shown in Figure 3. The SZ has a symmetrical bowl-like shape; its diameter is slightly larger than that of the sleeve, while its depth is much larger than the nominal plunge depth of the sleeve. This is most likely related to the history of the material flow. For the same reason, there is a special region at the edge of the SZ, named the "drop" region. In addition, there is a so-called joint-line remnant (JLR) within the SZ, which is similar but more continuous than that in FSW. In addition, the weld center possesses a different contrast, which is still most likely due to a special material flow behavior.

\section{B. Macroscopic Material Flow}

A JLR is interpreted as a remnant oxide film originating from the butt interface in FSW. ${ }^{[21]}$ In refill FSSW, the JLR appears to have the same experience; it originates from the faying surface or interface. Thus, its development may reflect the evolution of the interface between the upper and lower sheets. In this regard, we used this feature as a marker to trace the interface. To this end, the stop-action technique ${ }^{[11]}$ was adopted to freeze the weld at different plunge depths of the sleeve, i.e., 0.5 to $2.0 \mathrm{~mm}$, while the other parameters were kept constant.

Figure 4 shows the evolution of the JLR during the welding process. In general, in terms of the optical contrast, symmetrical deformation is formed around the weld and the deformation is much larger than the plunge depth. In the penetrating stage, materials from the bottom sheets progressively participate in the material 


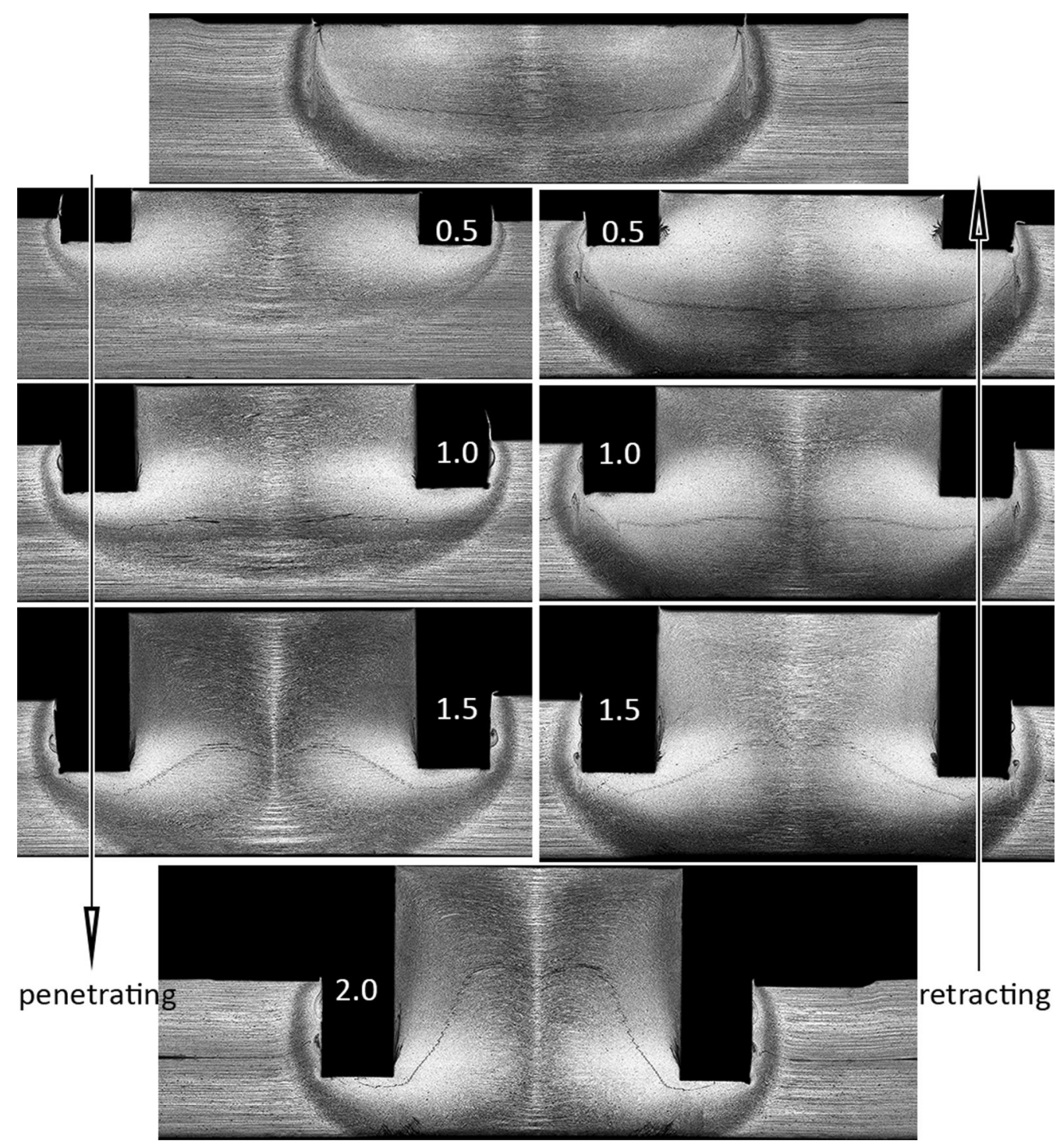

Fig. 4-Different stages of the welding process showing the macroscopic material flow indicated by the evolution of the joint-line remnant. The depth of the sleeve when the process was terminated is annotated on the corresponding figure.

Table II. The Calculated Volume of Material Beneath the JLR at Different Sleeve Depths Normalized by the Volume of the Material Beneath the Initial Between the Upper and Lower Sheets

\begin{tabular}{|c|c|c|c|c|c|}
\hline \multirow[b]{2}{*}{ Stage } & \multirow[b]{2}{*}{ Depth of the Sleeve } & \multicolumn{4}{|c|}{ Normalized Volume } \\
\hline & & Forward Side & Backward Side & Average & Standard Deviation \\
\hline \multirow[t]{4}{*}{ Penetrating } & 0.5 & 1.0280 & 1.0153 & 1.0217 & 0.0063 \\
\hline & 1.0 & 0.9648 & 1.0581 & 1.0115 & 0.0467 \\
\hline & 1.5 & 0.9699 & 1.0535 & 1.0117 & 0.0418 \\
\hline & 2.0 & 1.0391 & 0.9851 & 1.0121 & 0.0270 \\
\hline \multirow[t]{4}{*}{ Retracting } & 1.5 & 1.0147 & 0.9644 & 0.9895 & 0.0251 \\
\hline & 1.0 & 1.0513 & 0.9611 & 1.0062 & 0.0451 \\
\hline & 0.5 & 1.0437 & 0.9647 & 1.0042 & 0.0395 \\
\hline & 0 & 0.9985 & 0.9955 & 0.9970 & 0.0015 \\
\hline
\end{tabular}

The JLR profile is not perfectly symmetrical about the center, and therefore, the calculations were based on the forward and backward side separately. 

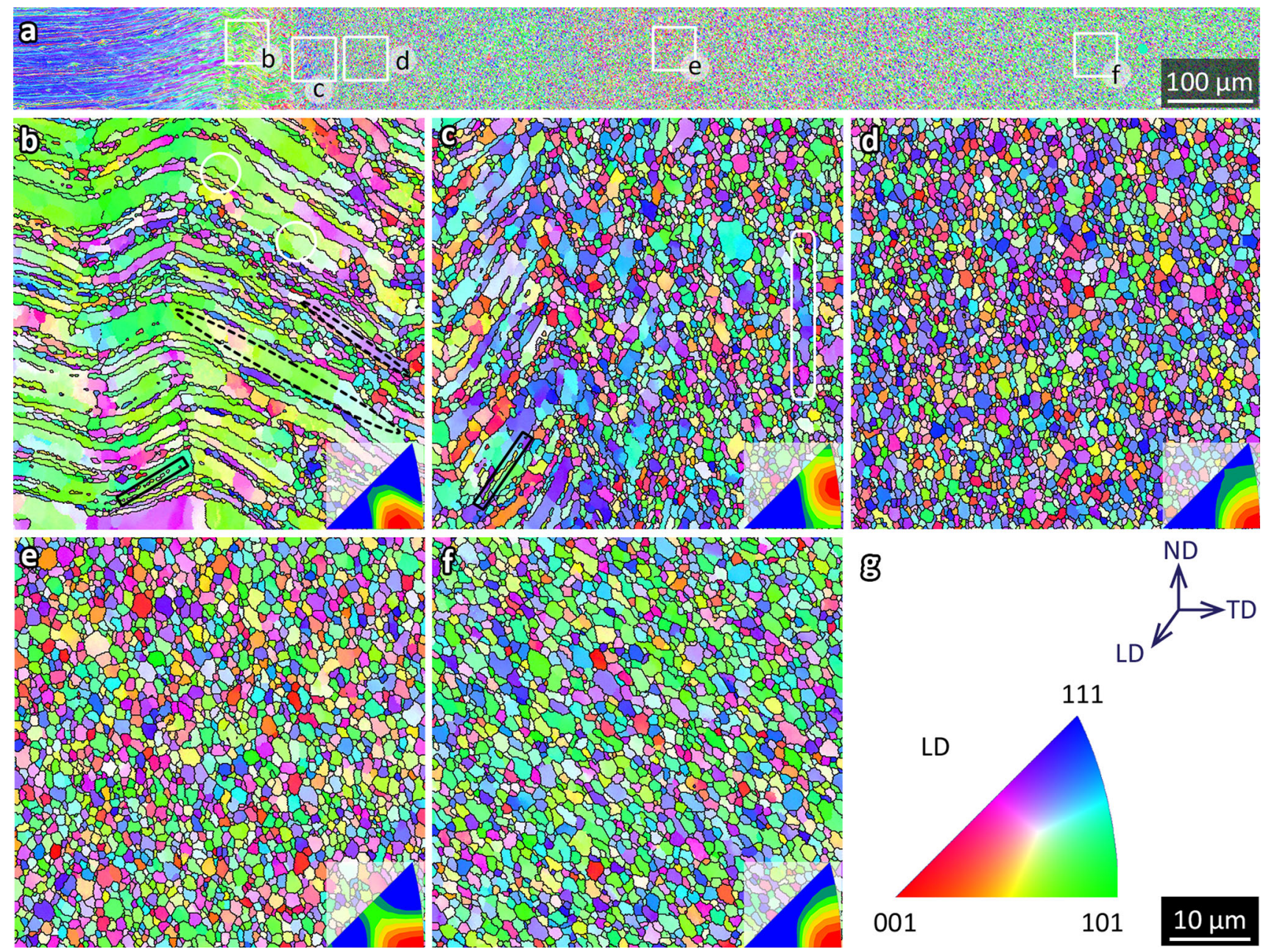

Fig. 5-Details of the transition area: (a) a composite EBSD map superimposed with white boxes b through $\mathrm{f}$ showing the locations of regions with different contrasts, $(b)$ through $(f)$ EBSD maps of each region with inserts showing the corresponding inverse pole figures, $(g)$ the reference frame and a triangle showing the color code (an individual pixel is colored according to its crystallographic direction relative to the LD) for EBSD maps, and the scale bar for $\mathrm{b}$ through $\mathrm{f}$.

Table III. Grain Structure Characteristics of Regions b Through f Shown in Fig. 5, as Well as the Peak Texture Intensity, and Volume Fraction of the Crystal Axes Orientated Within 10 Deg of Sample LD

\begin{tabular}{|c|c|c|c|c|c|c|c|}
\hline \multirow[b]{2}{*}{ Region } & \multirow[b]{2}{*}{ Grain Size $(\mu \mathrm{m})$} & \multirow[b]{2}{*}{ HAGB Fraction (Percent) } & \multirow[b]{2}{*}{ Peak Intensity (a.u.) } & \multicolumn{3}{|c|}{$\begin{array}{c}\text { Volume Fraction of Crystal } \\
\text { Direction (Percent) }\end{array}$} & \multirow[b]{2}{*}{ Contrast } \\
\hline & & & & $\langle 101\rangle / / \mathrm{LD}$ & $\langle 001\rangle / / \mathrm{LD}$ & $\langle 111\rangle / / \mathrm{LD}$ & \\
\hline b & 0.92 & 61.6 & 3.081 & 19.8 & 0.9 & 1.5 & bright \\
\hline $\mathrm{c}$ & 0.86 & 77.7 & 1.654 & 10.2 & 3.0 & 6.1 & dark \\
\hline d & 0.86 & 86.4 & 2.076 & 17.7 & 2.2 & 5.2 & bright \\
\hline $\mathrm{e}$ & 1.02 & 82.8 & 1.609 & 14.4 & 3.8 & 3.4 & dark \\
\hline $\mathrm{f}$ & 1.11 & 82.2 & 2.212 & 21.5 & 1.4 & 4.3 & bright \\
\hline
\end{tabular}

flow; the initial interface becomes deformed even when the plunge depth is $0.5 \mathrm{~mm}$. As the sleeve penetrates, due to its extrusion effect, the peak of the JLR moves upwards while the foot moves downwards. At the same time, the middle of the JLR gets more and more concave, which is most likely caused by the compression effect of the pin. In the retracting stage, the process reverses: the peak of the JLR moves downwards, the root moves upwards, and the middle becomes flat.

Interestingly, the JLR always seems to be continuous during the whole process, with the exception of when the plunge depth is so large (e.g., $2 \mathrm{~mm})$ that the motion of the sleeve breaks the JLR around the sleeve. In all phases, it likely behaves as the border between the upper 


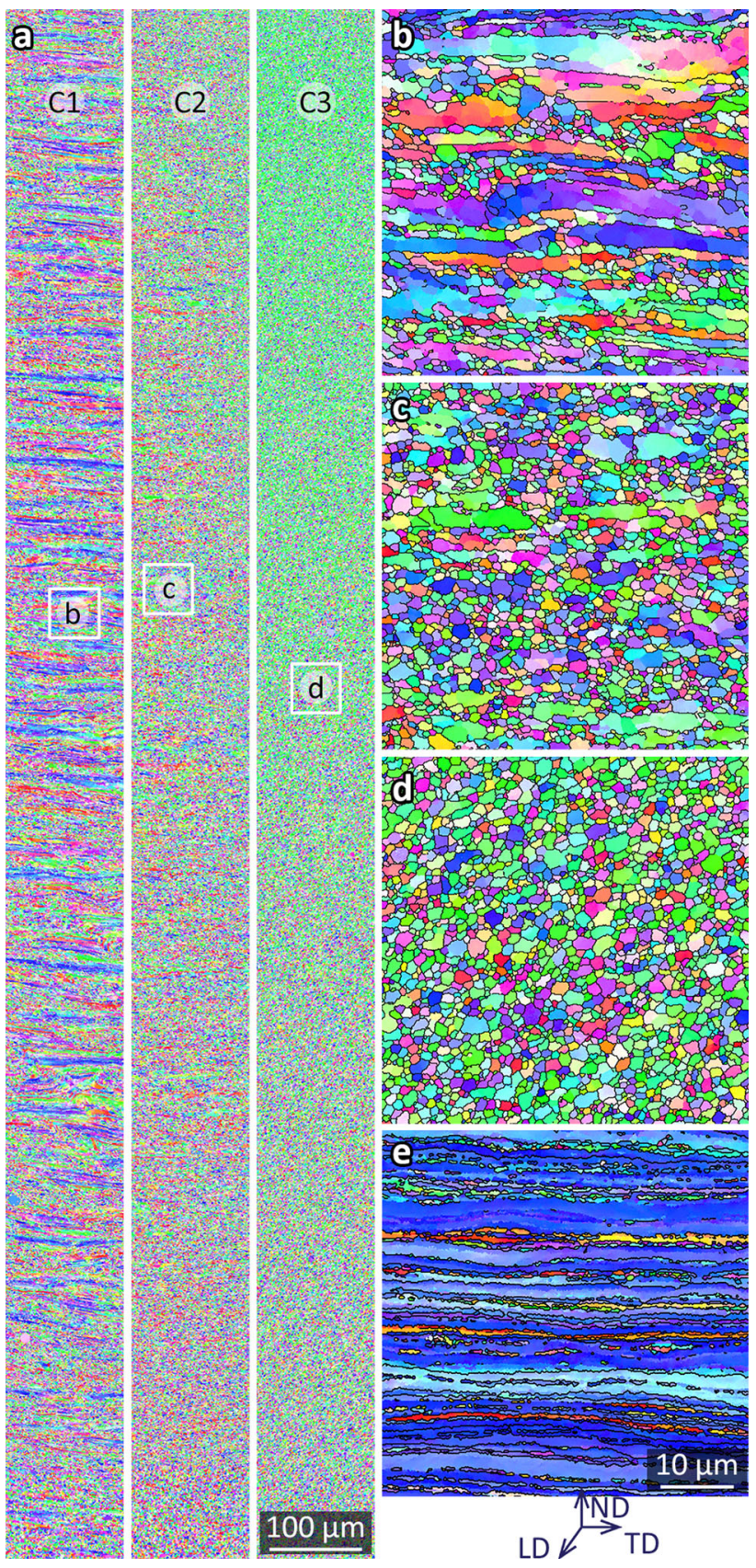

Fig. 6-EBSD maps showing the variation in microstructures with the SZ. (a) An overview of columns C1 (the upper part, above R3), $\mathrm{C} 2$, and $\mathrm{C} 3$, superimposed with white boxes $\mathrm{b}$ through $\mathrm{d}$ showing the locations of regions $\mathrm{b}$ through $\mathrm{d}$. (b) through $(d)$ details of locations $\mathrm{R} 2 \mathrm{C} 1, \mathrm{R} 2 \mathrm{C} 2$, and $\mathrm{R} 2 \mathrm{C} 3$, respectively. (e) A representative EBSD map of the BM. $b$ through e has the same scale bar. The reference frame and coloring schema are the same as in Fig. 5.

and lower sheets. To check this idea, the volume of the material beneath the JLR is estimated by the approach mentioned in the Supplementary Data. The approximate nominalized volumes are listed in Table II. Indeed, the volume of the materials beneath the JLR and the initial interface changes little, less than $2.2 \mathrm{pct}$, during the entire welding process. In this sense, the macroscopic vertical material flow between the upper and lower sheets is not obvious. The evolution of the JLR offers hardly any information on the local material flow, which will be discussed later.

\section{Development of the Microstructure in the Transverse Cross Section}

\section{The transition area}

As shown by a rectangle $\mathrm{T}$ in Figure 3, the local contrast varies alternately at the border between the TMAZ and the SZ. There is a sharp bright band, i.e., the drop region, around the regions close to the trace of the outer edge of the sleeve. The drop region was first emphasized in $\mathrm{Al} / \mathrm{Cu}$ dissimilar welds, ${ }^{[13]}$ although similar regions also existed in similar aluminum and magnesium refill friction stir spot welds. In that study, the special optical contrast is independent of the local elemental composition, e.g., the formation of intermetallic compounds, which always causes a difference in contrast.

Figure 5 shows the details of the regions with different contrasts. Apart from region b, which is located in the TMAZ, all the other regions have recrystallized grain features. To better understand the differences among these regions, the grain structure characteristics of regions b-f as well as the peak texture intensities and volume fractions of the crystal axes orientated within 10 deg of sample LD are listed in Table III. Unlike in the $\mathrm{Al} / \mathrm{Cu}$ dissimilar weld, where the refined grains may contribute to differences in optical contrast, the grains of different regions have no marked changes in grain size or fraction of HAGBs. Based on the inverse pole figures (IPFs), the texture shifts slightly from one region to another, although in all regions the pronounced crystallographic orientation is $\langle 101\rangle / / \mathrm{LD}$. This most likely accounts for the corresponding change in optical contrast. Indeed, the extracted fraction of each texture component from the IPF shows the same variation as the contrast. The brighter regions correspond to higher fractions of $\langle 101\rangle / / \mathrm{LD}$, approximately 17.7 to $21.5 \mathrm{pct}$, while the darker regions correspond to lower fractions of $\langle 101\rangle / / \mathrm{LD}$, approximately 10.2 to 14.4 pct. Surely, this trend is also manifested by the variation in the peak texture intensity.

\section{The $S Z$}

As mentioned earlier, the weld center shows differences in optical contrast. To better understand the changes at different locations, several EBSD scans were performed. Figure 6 shows the composite EBSD maps from columns $\mathrm{C} 1-\mathrm{C} 3$ as well as representative details. The weld center has grains with mixed features, i.e., equiaxed and fibrous, which is usually considered a feature of partial recrystallization; this feature is uncommon in FSW. Away from the center $(\mathrm{C} 1)$, the weld shows less partial recrystallization. When $\mathrm{C} 2$ is reached, $0.2 \mathrm{~mm}$ away from $\mathrm{Cl}$, it is difficult to see fibrous grains. This trend likely corresponds to the change in optical contrast shown in Figure 3. This phenomenon, however, has not been observed by EBSD elsewhere. Nevertheless, the difference in optical contrast can also be found in refill FSSW of AA2198. ${ }^{[7]}$ Thus, this difference could 


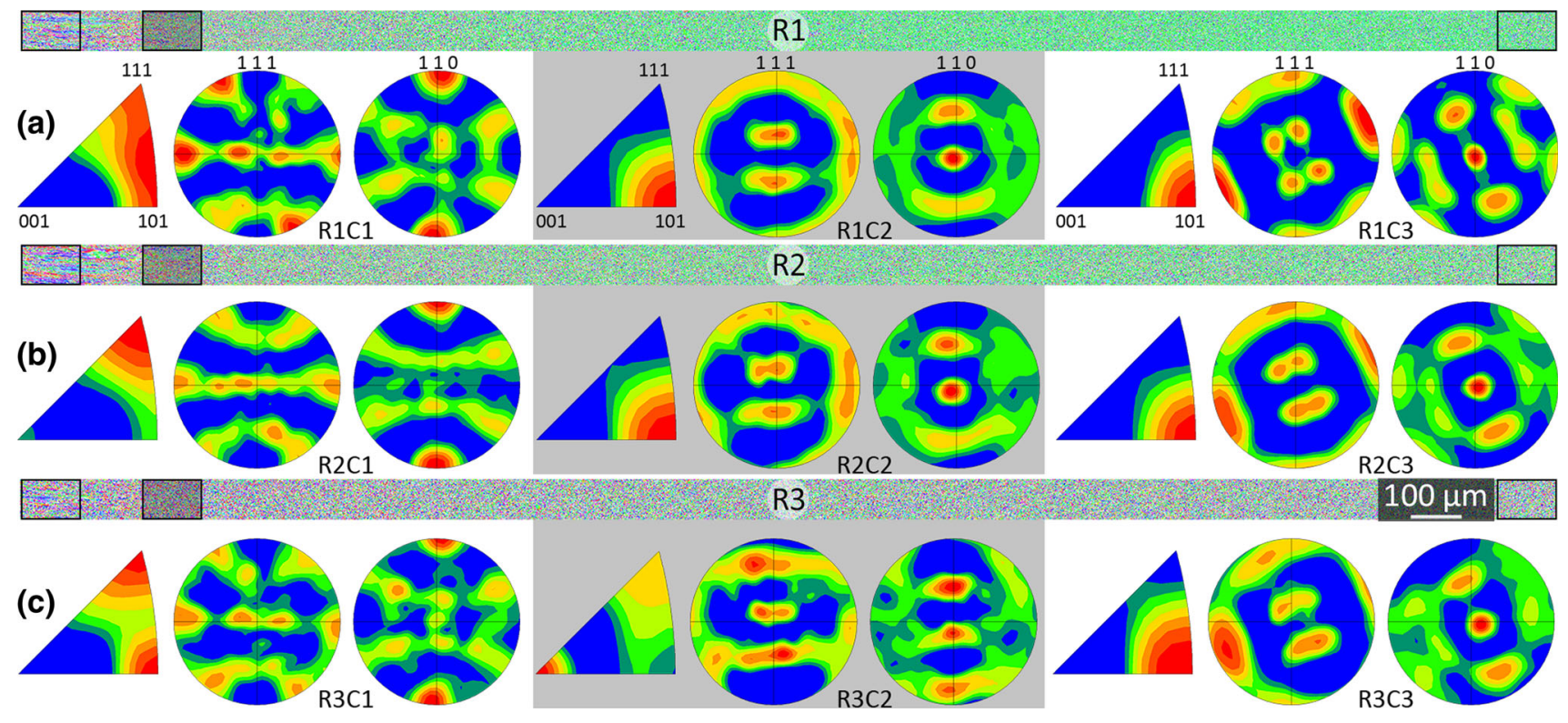

Fig. 7-EBSD maps showing the variation in textures with the SZ. Overview of rows $(a) \mathrm{R} 1,(b) \mathrm{R} 2$, and $(c)$ R3, along with as-acquired IPFs and (111) and (110) PFs from the locations indicated by the rectangles (a) R1C1, R1C2, R1C3, (b) R2C1, R2C2, R2C3, and (c) R3C1, R3C2, $\mathrm{R} 3 \mathrm{C} 3$, respectively. (a) through (c) have the same scale bar. The reference frame and coloring schema are the same as in Fig. 5.

depend on the material to be welded and is most likely related to the special material flow mode, which will be discussed later. Moreover, the microstructural features shown in the weld center are also quite different from the BM (Figure 6(e)). Therefore, the weld center may not be simply inherited from the cold-rolled BM.

Figure 7 shows the composite EBSD maps as well as the as-acquired IPFs and PFs from rows R1-R3. Again, corresponding to the change in contrast, the weld center possesses a different orientation. From the IPFs, the most common orientations can be recognized as $\langle 111\rangle / /$ $\mathrm{LD}$ and $\langle 110\rangle / / \mathrm{LD}$, while in the other regions, i.e., regions $\sim 0.2 \mathrm{~mm}$ away or farther, another orientation $\langle 110\rangle / / \mathrm{LD}$ (with spread about LD) is predominant. Along the columns, the orientation remains unchanged from the top to bottom, although it is slightly more scattered when the bottom is approached. This can also be seen from Figure 6 where the entire regions along these three columns are provided. Additionally, compared to the rolling texture of the $\mathrm{BM}$, these regions in the weld center have completely different textural features, which will be discussed later.

\section{Development of the Microstructure in the Horizontal Cross Section}

Figure 8 shows the composite EBSD map taken from the horizontal cross section, along the radial direction and parallel to the TD (RTD); on this plane, the weld center is unlike that determined from the transverse cross section (see Figure 6). The grains appear equiaxed and recrystallized rather than partially deformed. Actually, all the regions under the pin have the same grain features. The reason will be discussed later. Moreover, around the weld center, the as-acquired PFs most likely undergo a rotation about the weld center, which means that the weld center has a special material flow mode. When moving away from the weld center, starting from location 8i, the as-acquired PFs show minor changes. The cross section most likely does not align very well during sample sectioning/slicing because all the PFs have the same rotation about the ND.

To confirm the obtained grain features, another rectangle that aligns RLD (along the radial direction and in parallel with the LD) was examined, as shown in Figure 9. Interestingly, no grains with partial recrystallization features can be detected along the entire rectangle RLD (i.e., $4.5 \mathrm{~mm}$ long). Additionally, the rotation about the ND is absent in this direction. To interpret this, one hypothesis will be given in the following discussion.

These results from the horizontal cross section seem to be different from those from the transverse cross section. Thus, the PFs from some representative locations of the transverse cross section, i.e., the weld center, the location under the pin, the location at the inner and outer edge of the sleeve, and the equivalent position of the horizontal cross section, are compared, as shown in Figure 10. As expected, the PFs from the RLD and RTD show a 90 deg rotation about the ND regardless of the location (see Figures 10(c) and (d)). In addition, in the horizontal cross section, the PFs from the RTD show a $90 \mathrm{deg}$ rotation (in the negative direction) about the TD relative to those from the equivalent positions of the transverse cross section, with the exception of the weld centerline. This can be explained by the fact that the sectioning is not exactly equivalent. As shown in Figures 6(a) and (b), the weld center possesses grains of mixed features; they do not have exactly the same textural characteristics.

To better understand the material flow mode, an appropriate coordinate reference frame needs to be 


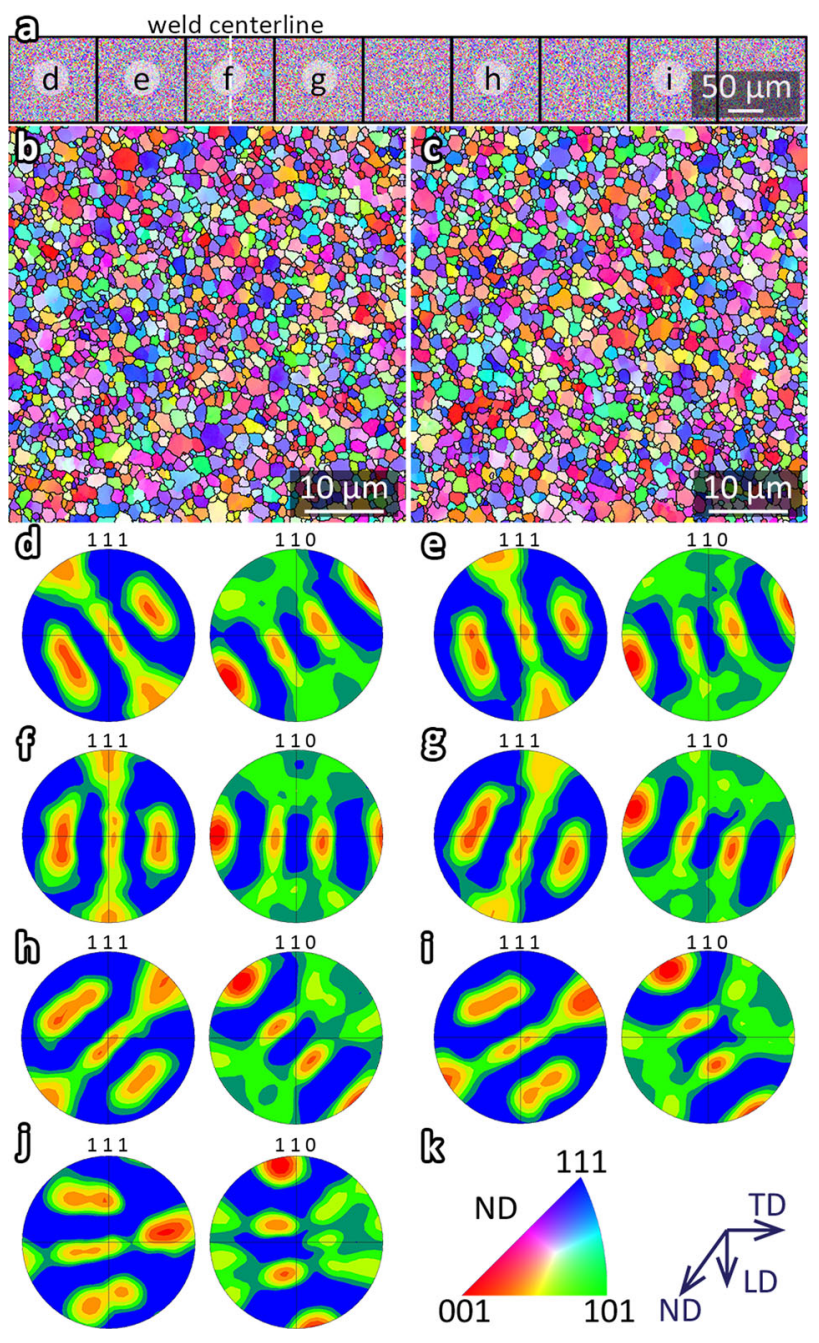

Fig. 8-Composite EBSD maps and (111) and (110) PFs showing the variation in microstructure and textures along the rectangular RTD in the horizontal cross section. (a) The overview and indications of locations d through $\mathrm{i},(b)$ magnified view of location $\mathrm{f}$, i.e., the weld center, $(c)$ magnified view of location $g,(d)$ through $(i)$ the corresponding PFs of locations d through $\mathrm{i},(j)$ the PFs obtained from the inner edge of the sleeve, and $(k)$ the reference frame and coloring schema.

established. It is thus critical, especially for face-centered cubic (fcc) crystals, to accurately establish the actual reference frame to recognize the observed textures ${ }^{[15]}$ and thus better reflect the actual physical process, i.e., material flow. Based on the IPFs in Figure 7, all the regions except the center in the weld have the same orientation $\langle 110\rangle / / \mathrm{LD}$, which is quite similar to the high-temperature compression texture found in an AlMgSc alloy ${ }^{[22]}$ if the LD is parallel to the compression axis. From the (111) PFs, however, the (111) poles are always concentrated in some positions, which implies there should be another stricter orientation relation than the compression texture. Moreover, if the compression texture is the case, it will not be self-consistent in terms of symmetry; any cross section through the weld center should be equivalent.
In FSW, the physical process is simplified as a simple shear, which uses the simple shear frame, i.e., the shear plane normal (SPN) and the shear direction (SD). Refill FSSW, however, is quite different, even compared to the basic FSSW. Nevertheless, the process is likely comparable to the torsion process, where one end of the rod is fixed and the other one is subjected to a torque. In this sense, the material flow mode is close to the simple shear. Thus, the same rotation route as in FSW is adopted to align the SPN vertical and SD horizontal.

Prior to that, the SD needs to be determined. In the weld center, the shear direction is horizontal to the left because this is the only possibility. That is, at the weld centerline, the SD aligns with the TD (in the negative direction). From the PFs in Figures $8(\mathrm{f})$ or $10(\mathrm{c})$, the (110) poles pass through the endpoint of the TD axis; thus, the SD aligns with the $\langle 110\rangle$ direction. This most likely suggests $\mathrm{B} / \overline{\mathrm{B}}$ or $\mathrm{C}$ (the notation is adopted from $^{[23]}$ and used below), or both components. If this is the case, the SDs of all the regions surrounding the weld center has the same rotation relation as the PFs about the ND. In this sense, when the region is far enough away from the centerline, the SD tends to align with the LD, e.g., Figures 8(i) and (j).

During refill FSSW, only the sleeve penetrates into material, and hence, the material flow is primarily driven by the sleeve. When contacting the material, the end surface of the sleeve shears the material clockwise right below the surface. Therefore, in general, it is reasonable to infer that the shear plane is aligned with the end surface of the sleeve, that is, the SPN is aligned with the ND. However, this is not the only case. As shown in Figures 7 and 10, at the center and the outer edge of the sleeve, the SPN is inward (pointing to the center); when the inner edge of the sleeve is approached, the SPN tends to rotate about the LD.

Based on the above considerations, the PFs are rearranged to align with the SPN vertically and the SD horizontally, and the results are shown in Figure 10(b). To separate the components that partially overlapped in the PFs, the $\phi_{2}=0 \mathrm{deg}$ and $\phi_{2}=45 \mathrm{deg}$ sections from the orientation distribution function (ODF) plotted in Euler space using Bunge notations are presented as well. The locations of the ideal components of a simple shear texture for fcc metals are indicated on these images. The weld center could be interpreted as $\mathrm{A}_{1}^{*} / \mathrm{A}_{2}^{*}$ components with minor $\mathrm{C}$ components, and the remaining regions can be interpreted as $\mathrm{B} / \overline{\mathrm{B}}$ components with minor $\mathrm{A} / \overline{\mathrm{A}}$ and $\mathrm{C}$ components.

The difference in the texture formed in the weld center and the other regions is most likely related to the local shear strain. Previous studies suggest that the magnitude of the simple shear strain directly correlated with the components, i.e., component $\mathrm{C} / \mathrm{A}^{*}$ is dominant at smaller shear strains compared to component $\mathrm{B} / \overline{\mathrm{B}} .^{[24-26]}$ In this regard, the material was subject to lower shear strain in the weld center than in the other regions. 


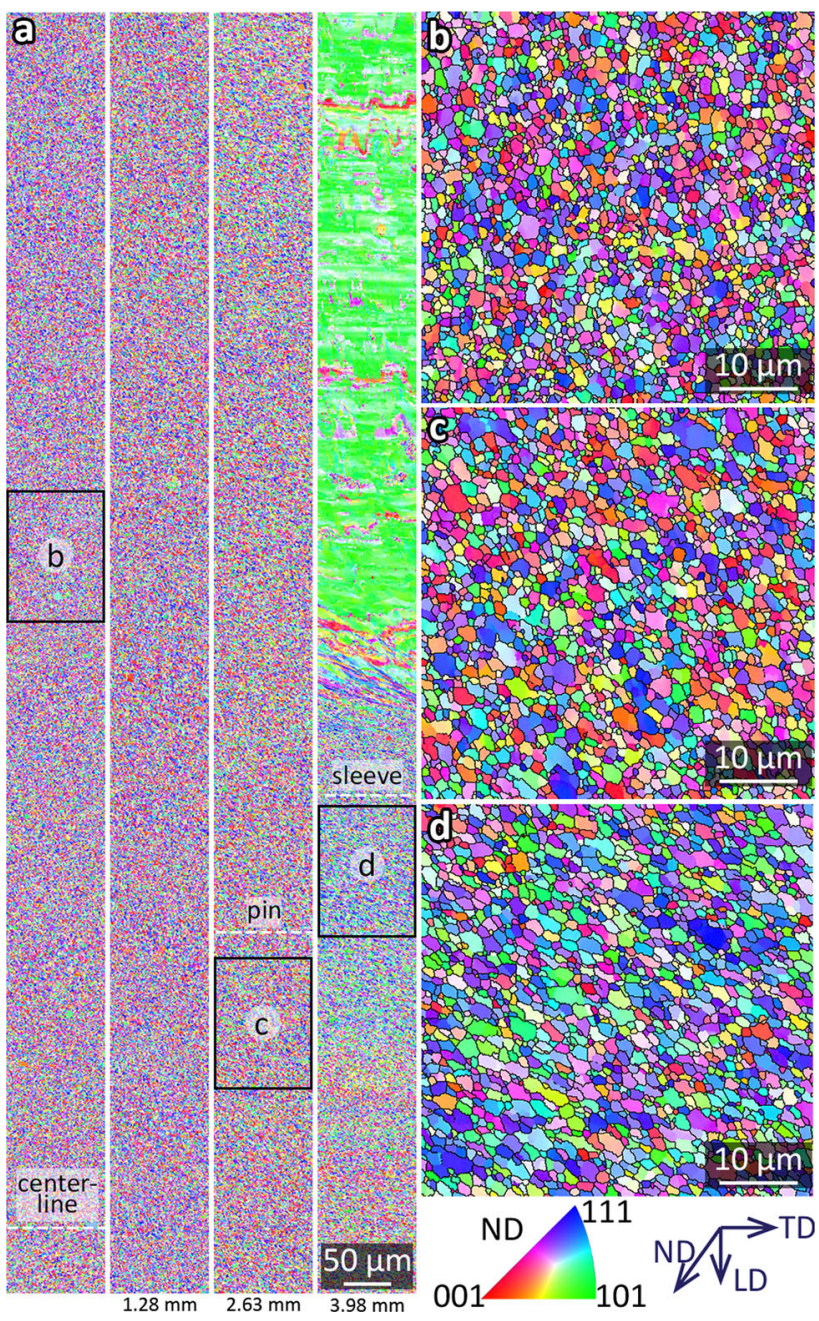

Fig. 9 - Composite EBSD maps showing the variation in microstructure along the rectangular RLD in the horizontal cross section. (a) An overview of the four slices, the distance from the centerline is indicated at the bottom, and the boxes indicate the locations of regions $\mathrm{b}$ through $\mathrm{d}$. (b) through (d) Magnified views of locations $\mathrm{b}$ through $\mathrm{d}$.

\section{DISCUSSION}

\section{A. Subdivision of the Weld}

As shown in Figure 3, the shape of the $\mathrm{SZ}$ is different from those commonly found in FSW or in refill FSSW. As defined in FSW, the TMAZ is the zone surrounding the SZ, where the material underwent plastic deformation but recrystallization did not occur because there was insufficient deformation strain. In this sense, the weld center may not be included in the SZ. If so, this definition most likely does not represent the general situation for all materials. Thus, the upper part of the weld center is still classified in the SZ; however, the lower part is different.

There are two main differences as shown by the microstructural evolution in the regions around the bottom of the SZ (Figure 11) and the variation in grain structures and peak texture intensities in the same regions (Figure 14(a)). At the very bottom of the weld
(Figure 11(a)), those textural patterns appear close to the rolling texture of the BM with some shift toward the rotating direction. As distance from the weld bottom increases, the rolling texture shifts progressively to shear texture, and when approaching the SZ, texture pattern stabilizes but generally decreases in peak intensity. In contrast, the grain structure does not change at the same pace. In region $11 \mathrm{~b}$, the grains have similar features to those shown in Figure 6(b), i.e., partial recrystallization, while the neighbor region beneath (Figure 11(c)) has grains with more predominant fibrous features, as confirmed by the fraction of recrystallized grains (Figure 14(a)). These characteristics most likely suggest that region $11 \mathrm{~b}$ should be classified as the border of the SZ. However, the concave-bottomed shape of the SZ is unnecessary for all materials because this is most likely related to the recrystallization behavior of the BM.

Concerning the SZ, recrystallized features are found in all regions except the ones close to the weld center, which is characterized by partial recrystallization. There could be two reasons for the difference in local recrystallizing behavior. First, the weld center was subjected to minimal shear strain, and thus, the driving force for recrystallization is relatively small, and the recrystallization kinetics are slow, whereas for other locations, the local shear strain is sufficient. Essentially, this difference is caused by the material flow. Second, it is most likely related to the material itself: $\mathrm{AlMgSc}$ alloys are famous for the anti-recrystallization effect due to the pinning effect of $\mathrm{Al}_{3} \mathrm{Sc}$ dispersoids, ${ }^{[27-29]}$ which is most likely why such a structural characteristic is uncommon for other Al alloy refill friction stir spot welds.

\section{B. Material Flow Modes}

As shown in Figures 7 and 10, the SD is perpendicular to the TD and parallel to the LD in all regions in the transverse cross section. This behavior is different from the FSW where the SD deviates from the TD in the deposited weld as a function of position across the weld ${ }^{[15]}$ due to the sweeping and traversing motion of the tool. This implies a different material flow route around the sleeve/pin in refill FSSW. Figures 12 and 13 show hypothetical schematic diagrams illustrating the material flow model in the horizontal and transverse cross sections, respectively. The forward side is defined as where the material moves the paper inwards, and the backward side is where the materials move the paper outwards. For simplicity, the influence of the dwelling stage is not considered in this model.

Using this model, the change in the SPN of different locations can be easily interpreted. The material deposited under the pin was subjected to a horizontal shear due to the rotating end surface of the sleeve, and therefore, the shear plane aligns with the end surface of the sleeve or the SPN is upward. The flowing of the material deposited close to the inner side of the sleeve is influenced by the edge effect of the sleeve, and thus, the SPN is slightly rotated about the LD (Figures 7 and 10). While close to the outer edge of the sleeve, the material flow is primarily governed by the side surface of the sleeve, as shown in Figures 13(a) and 10, and thus, the 
(a)
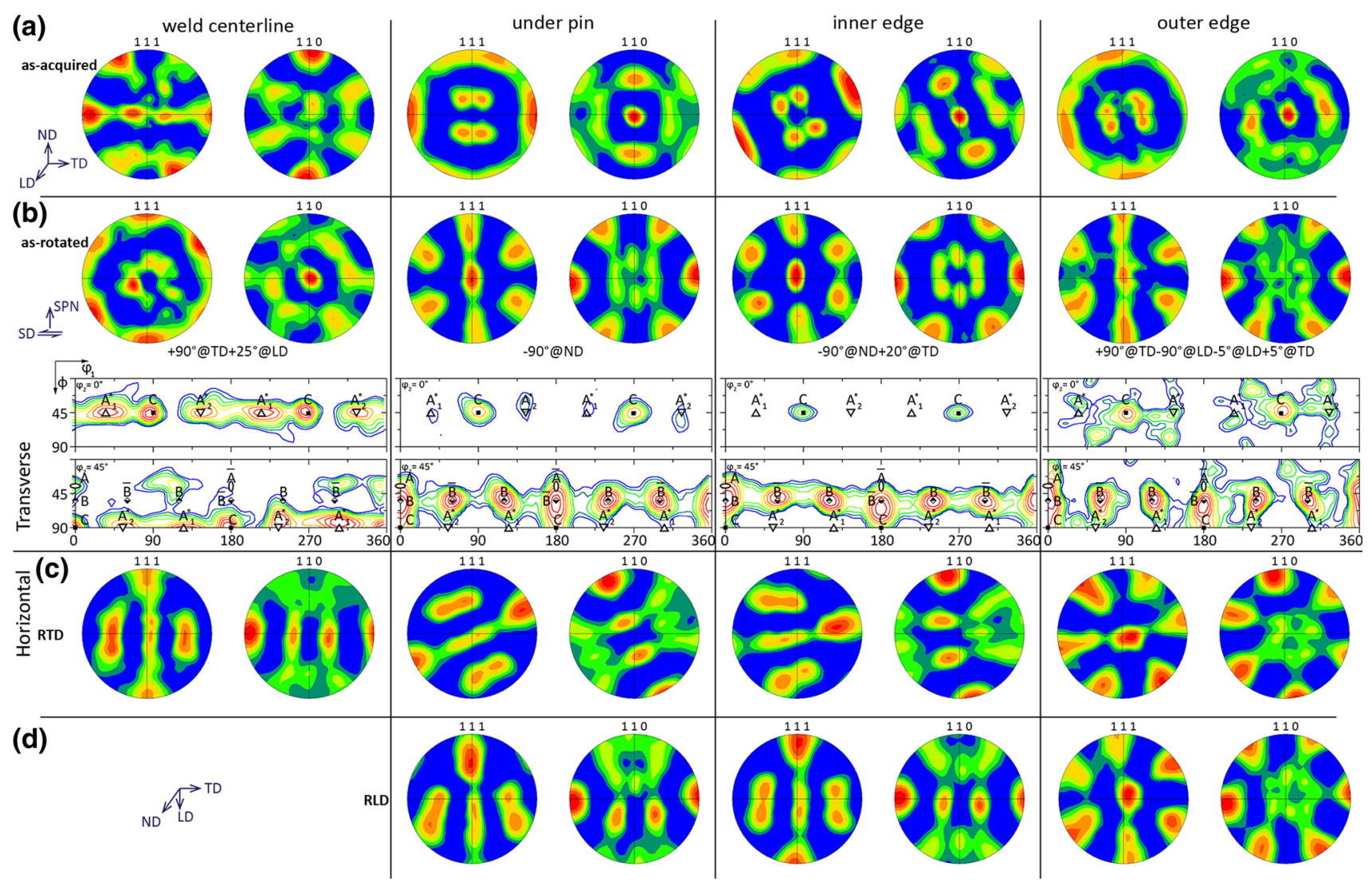

Fig. 10 - (111) and (110) PFs and ODFs determining the material deformation mode in various locations. (a) As-acquired PFs from the transverse cross sections and $(b)$ rotated PFs of a to align the shear direction horizontally along with the corresponding ODFs; as-acquired PFs from the horizontal cross sections: $(c)$ along the RTD and (d) along the RLD. All ODFs are sectioned from $\phi 2=0$ and 45 deg. The regions are at four different locations in the SZ: the weld centerline, the weld under the pin, and the welds on the inner edge and the outer edge of the sleeve.

SPN aligns inward (pointing to the center). In the weld center, however, the material flow is more complicated because two groups of material with opposite flow directions meet each other.

Thus, the formation mechanism of the weld is proposed as follows. First, at the beginning of the penetrating stage, the material in contact with the sleeve will be sheared horizontally and extruded into the cavity left by the upward moving pin. As the sleeve is penetrated, the same process will occur in more material beneath the sleeve end surface, which pushes the material inside the cavity upwards. In this manner, a plasticized rod grows up with the flow pattern like a "conical compression spring", as shown in Figure 13(a). Second, when the refilling stage begins, the pin moves downward, and the sleeve retreats. The material at the bottom of the rod is compressed and sheared into the keyhole left by the upward moving sleeve, and finally, this material is welded together with the keyhole, i.e., the material closely surrounding the sleeve, forming the drop region (Figure 13(b)). As the pin moves further downward, more material at the bottom of the plasticized rod follows the same route until the process ends.

As shown in Figure 13, the flowing of material into the cavity left by the pin is similar to a stack where the first layer is pushed by the second without jumping. The material from the upper shear flowed into the cavity followed by those of the lower sheet. In the refilling stage, the flowing of material is reversed, i.e., the material from the lower sheet is first extruded out of the rod and into the keyhole left by the sleeve, which is followed by that of the upper sheet. This behavior most likely accounts for the fact that the vertical material flow is not obvious between the upper and lower sheets (Figure 4). This kind of stack is most likely difficult to form in dissimilar metal combinations, especially when the material properties are clearly different. Additionally, this feature can be broken by changing the welding parameters, such as imposing a sufficient dwelling stage.

In essence, there are two types of material flow during the process: the horizontal component from simple shearing and the vertical component from extrusion. Thus, the real material flow path is a spiral curve. However, another material flow-related feature, a hook, is not included in this work, which deserves further attention.

\section{Recrystallization Mechanism}

The ultrafine-grained SZ is one of the most interesting features for FSW, and the involved mechanism of how it develops has been studied in a large number of works. Now, the fact that the transition from LAGB to HAGB is governed by multiple factors rather than a single one 

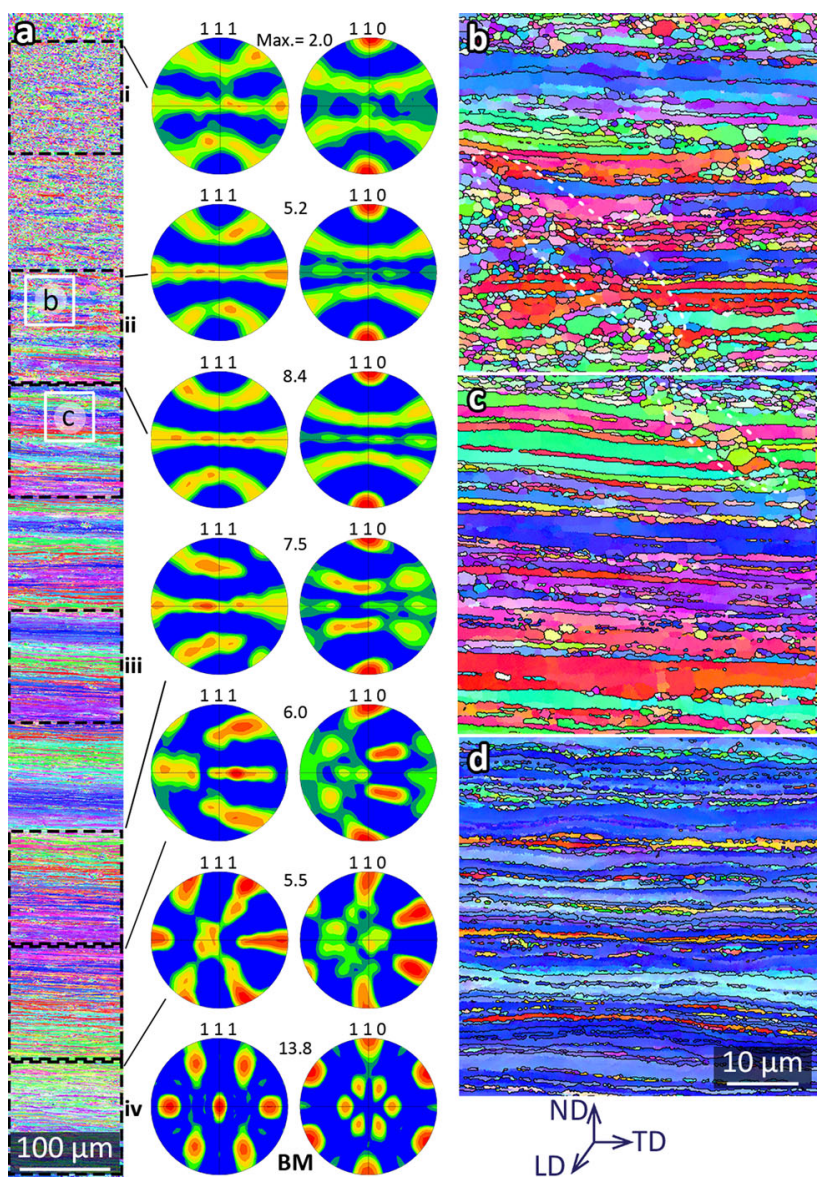

Fig. 11-Microstructural evolution around the bottom of the SZ: $(a)$ (111) and (110) pole figures showing the textures of selected regions of the lower part of column C1 (below R3), (b) through (d) EBSD maps of the region approaching the border of the SZ/TMAZ, the region located in the TMAZ, and the BM, respectively. The peak texture intensity is listed on each PF.

has become more well known. For FSW of aluminum alloys, the formation of refined grains has conclusively been determined to be a complex process driven by the geometric effects of strain, grain subdivision, and thermally activated HAGB migration, such as geometric dynamic recrystallization. ${ }^{[30]}$ This is most likely also the case for refill FSSW. At the edge of the TMAZ (Figure 5(a)), the grains are elongated and distorted due to the geometric requirements of strain, thereby decreasing the average HAGB spacing and increasing its fraction. Close to the border of the SZ, elongated fibrous grains under subdivisions (marked by dashed black ellipses in Figure 5(b)), retained fibrous fragments (marked by a white rectangle in Figure 5(c)), serrated HAGBs (marked by white circles in Figure 5(b)), closely spaced parallel HAGBs, and strings of fine grains (marked by black rectangles in Figures 5(b) and (c) are present; all of these features are in line with the definition of geometric dynamic recrystallization.

As demonstrated earlier, in refill FSSW, the deposited material primarily originates from the bottom, and thus, the development of the TMAZ under the bottom may provide more relevant information about the formation

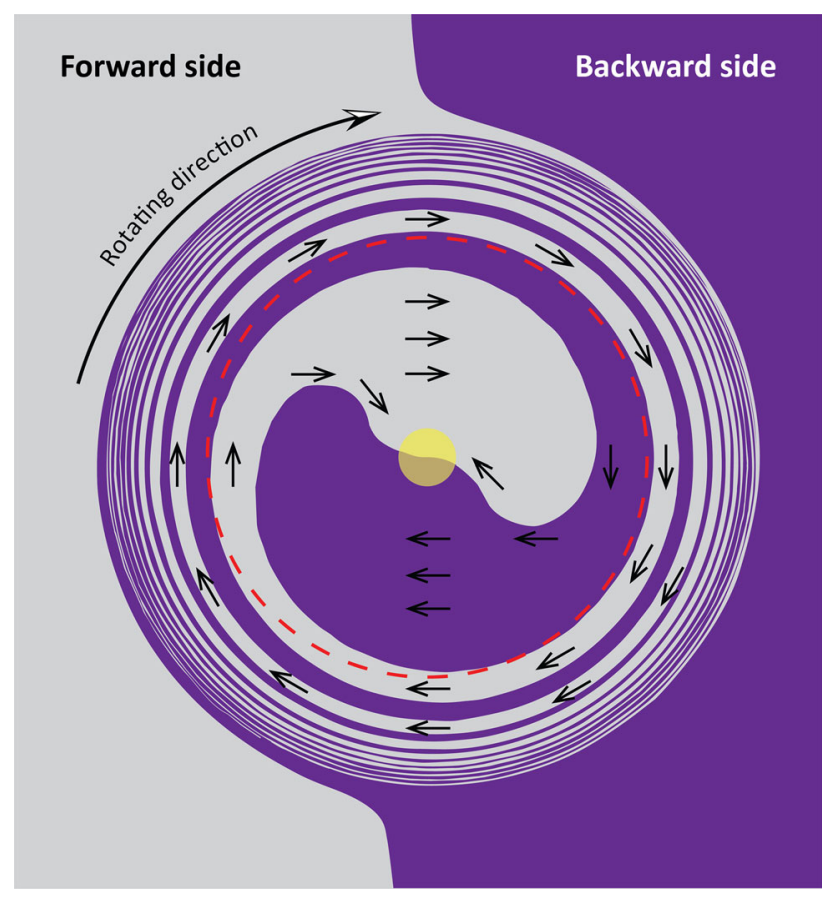

Fig. 12-A schematic diagram illustrating the material flow in the horizontal cross section. Different colors indicate the hypothetical material on the forward and backward sides. The pattern within the range of the pin is most likely random. The forward side is defined as where the material moves the paper inwards, and the backward side is where the materials move the paper outwards.

of ultrafine grains. In general, the bottom of the TMAZ shows more deformation inhomogeneity (Figures 11 and 14(a)). The geometric effects of strain and grain subdivision still play roles in the earlier stages of welding, manifested by the increased fraction of HAGB (Figure 14(a)) and diverged texture orientations inside the fibrous grains (Figure 11(b)). Meanwhile, the EBSD map also shows some unexpected features, such as the shear band (outlined by the dashed white oval in Figure 11(b)) and the twin (shown in Figure 11(c) and highlighted in Figure 15(a)).

The shear band is prone to occur in $\mathrm{Al}-\mathrm{Mg}-\mathrm{Sc}-\mathrm{Zr}$ alloys during severe plastic deformation. ${ }^{[31]}$ It is the result of local inhomogeneous plastic deformation and involves the rotation of lamellar structures in the deformed microstructure. ${ }^{[32,33]}$ The tendency for shear band formation increases with strain or strain rate and decreases with temperature. ${ }^{[34]}$ The existence of twin can be deduced by the change in the fraction of $\Sigma 3$ (Figure 14(a)) and the distribution of misorientation angles (Figure 14(b)) in the regions along column $\mathrm{C} 1$. Figure 15 shows individual grain orientation measurements in the twinned region (see also Figure 11(c)) and the misorientation distribution across those grains. It suggests that $60 \mathrm{deg}$ twinning about the $\langle 111\rangle$ axis occurs in the TMAZ during welding. This is unexpected. A recent study demonstrated for the first time that macrodeformation twins in high stacking fault energy materials, such as single-crystal $\mathrm{Al}$, are realized at ultrahigh strain rates $\left(\sim 10^{6} \mathrm{~s}^{-1}\right)$ and large shear strains (2). ${ }^{[35]}$ In the current work, however, the selected region 


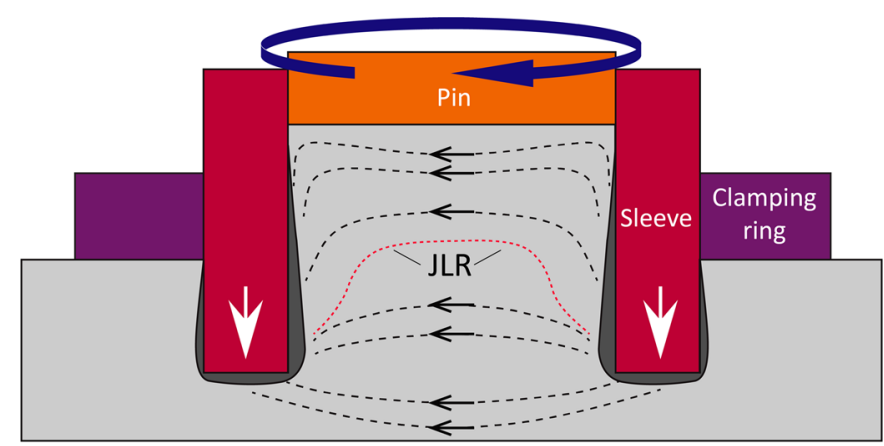

(a)

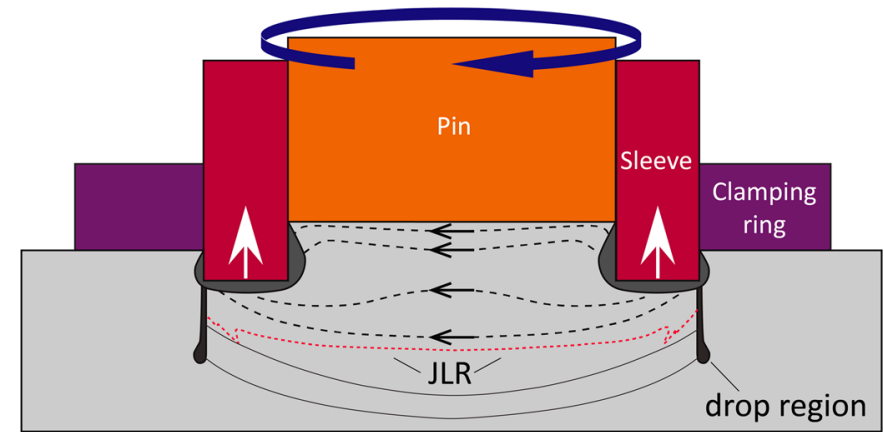

(b)

Fig. 13-Schematic diagrams illustrating the material flow in the transverse cross section: $(a)$ plunging stage and $(b)$ refilling stage. Material flow lines are indicated by dashes lines with the flow direction indicated by black arrows (see also Fig. 12). The white arrows show the moving direction of the sleeve.

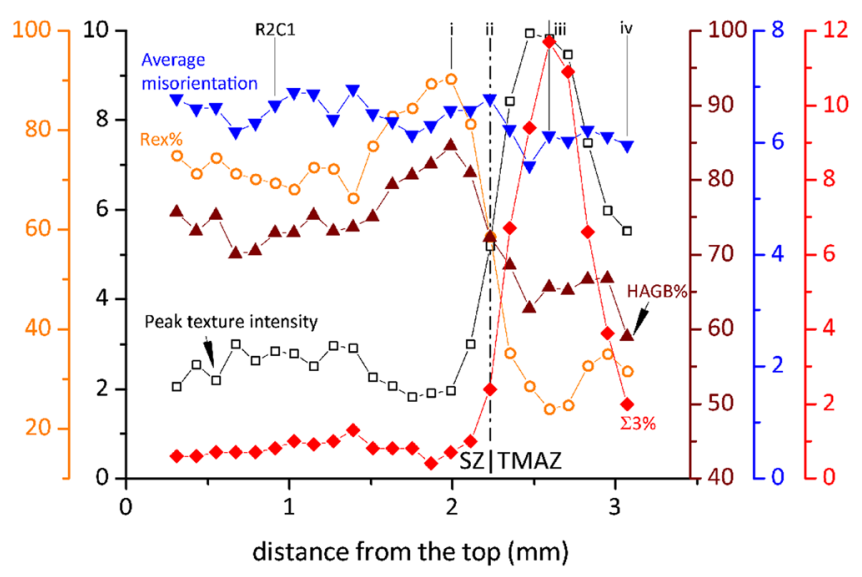

(a)

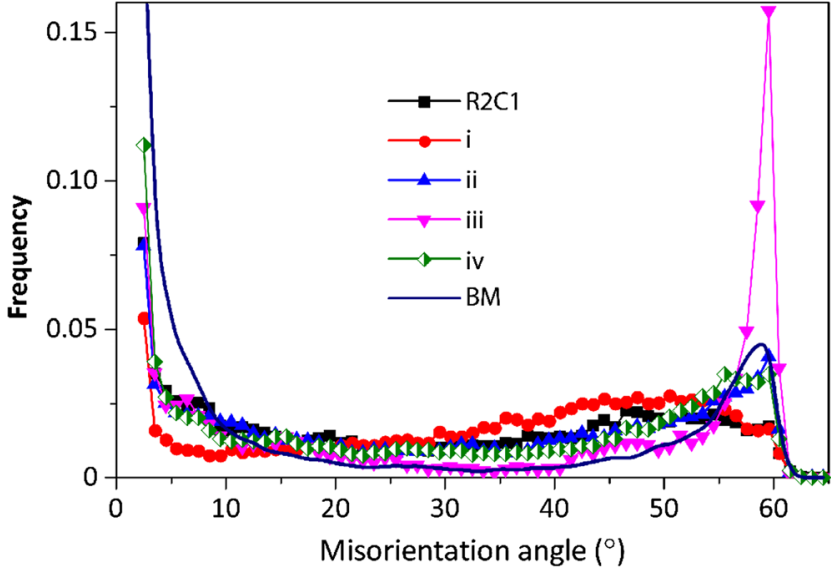

(b)

Fig. 14 (a) Evolution of the fraction of recrystallized grains (Rex pct), peak texture intensity, fraction of high-angle boundaries (HAGB pct), average orientation of the subgrains $(<15 \mathrm{deg})$, and area fraction of $\sum 3$ coincident site lattice boundary $\left(\sum 3\right.$ pct $)$ in the regions along column $\mathrm{C} 1$, and $(b)$ the distribution of subgrain/grain misorientation in locations $\mathrm{R} 2 \mathrm{C} 1$, $\mathrm{i}$ through iv (Fig. 11(a)), in comparison with that of the BM.

is close to the center, which would most likely not be expected to experience such a high strain rate with a large strain. Thus, some factors other than stain rate are responsible in this case. Lillywhite et al. have demonstrated that in an Al-Mg-Si alloy, annealing twins were found to develop in a significant number of the nucleating grains under conditions where fine particles retard the recrystallization behavior. ${ }^{[36]}$ In this way, the presence of a significant amount of $\mathrm{Al}_{3} \mathrm{Sc}$ dispersoids can reasonably facilitate the formation of twins, compromise the effect of Zener pinning, and thus improve the mobility of grain boundaries. This, however, deserves further investigation.

Nevertheless, both shear bands and annealing twins are generally associated with lattice rotation. These features most likely suggest that dynamic 


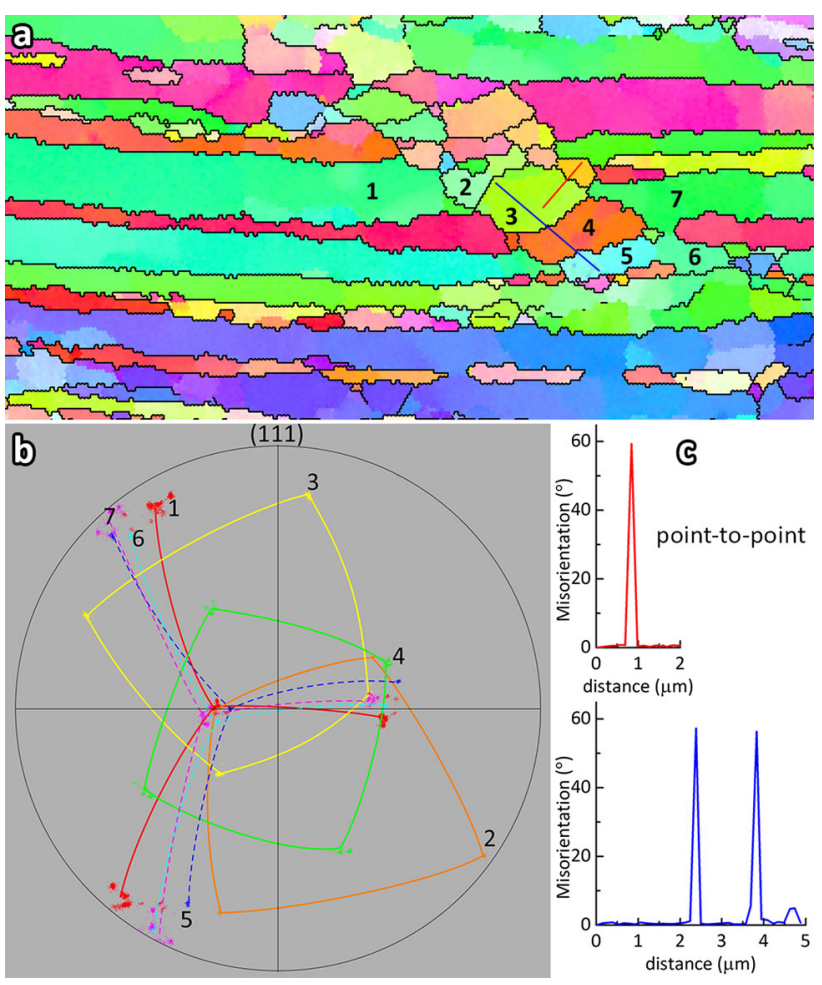

Fig. 15-Development of misorientation by lattice rotation adjacent to the grain boundary. (a) Magnified IPF map from Fig. 11(c), (b) (111) pole figure showing the orientation relationship among grains 1 through 7, indicated on a, and (c) misorientation line scans along the lines in red and blue on a, respectively.

recrystallization by progressive lattice rotation, i.e., continuous dynamic recrystallization, occurs at the bottom of the TMAZ, as is frequently found to occur at elevated temperatures in some aluminum alloys that contain high solute levels, such as Al-5 pct Mg, in which dislocation motion is inhibited by solute drag. ${ }^{[37]}$ This can also manifest as the average subgrain misorientation of approximately $6.4 \mathrm{deg}$ (see Figure 14(a)), which is much higher than expected $(<4 \mathrm{deg})$ in geometric dynamic recrystallization. ${ }^{[30]}$

The discrepancies in the recrystallization mechanisms on the side and bottom of the TMAZ are most likely related to the differences in thermal history and strain field. As indicated by inhomogeneous deformation features such as shear bands and twins, the boundary mobility at the bottom of the TMAZ is reduced, which implies that the bottom of the TMAZ experienced a lower temperature exposure along with a larger strain magnitude. In contrast, the solute drag effect is weaker on the side of the TMAZ under higher temperature exposure and smaller shear strain, thus accommodating more homogeneous deformation and geometric dynamic recrystallization. If this is the case, the formation of the final SZ microstructure is controlled by geometric dynamic recrystallization at the periphery and by continuous dynamic recrystallization in the remaining part.

\section{CONCLUSIONS}

The present study examined the formation of an AlMgSc joint welded by refill FSSW.

(1) The evolution of the JLR during the welding process reflects the macroscopic material flow characteristics. During all phases of welding, the volume of the materials separated by the JLR remained unchanged, which implies that the macro material flow is restricted within the JLR.

(2) In the transition areas close to the drop region, the variation in contrast correlates to the fraction of the $\langle 101\rangle / / \mathrm{LD}$ texture.

(3) The global straining state during refill FSSW was characterized as simple shear with the shear surface approximately along the sleeve/pin side surface at the weld center and edge, while along the sleeve/pin end surface in the other regions. The textural pattern was interpreted as a superimposition of $\{111\}$ - and $\langle 110\rangle$ - partial fibers with pronounced $\mathrm{A}_{1} * / \mathrm{A}_{2}{ }^{*}$ components in the weld center and with pronounced $\mathrm{B} / \overline{\mathrm{B}}$ components in the other regions.

(4) The center of the SZ is partially recrystallized due to the relatively low local shear strain. The bottom border of the SZ is determined by EBSD and characterized by an evident increase in fibrous structures as well as textural peak intensity. Using this approach, the defined SZ has a concave bottom, unlike what is estimated in the literature from optical microscopy. However, such a shape most likely more accurately represents the material flow history and recrystallization characteristics.

(5) Based on the texture results obtained from the transverse and horizontal cross sections, a material flow model is proposed. The material flow is mainly driven by two components: the simple shear acting on the horizontal plane and the extrusion acting on the vertical plane. During the penetration of the sleeve, the trace of one layer of material flow builds a spiral curve, similar to a conical compression spring, while during the refilling stage, such a spring is progressively compressed into a plane. In both stages, the material flows occurs layer by layer, and thus, the vertical material flow between the upper and lower sheets is unobvious.

(6) Recrystallized features are found in all regions of the SZ except the ones close to the center, which are dominated by partial recrystallization. This is believed to be related to the magnitude of the local shear strain and affected by $\mathrm{Al}_{3} \mathrm{Sc}$ dispersoids. The formation of refined grains is a complex process that is driven by the geometric effects of strain, grain subdivision, and thermally activated HAGB migration, such as geometric dynamic recrystallization at the periphery of the SZ and continuous dynamic recrystallization by lattice rotation in the other parts. 


\section{ACKNOWLEDGMENTS}

The authors are grateful to Professor Prangnell from The University of Manchester for helpful discussions.

\section{ELECTRONIC SUPPLEMENTARY MATERIAL}

The online version of this article (doi: 10.1007/s11661-017-4381-6) contains supplementary material, which is available to authorized users.

\section{REFERENCES}

1. S. Fukumoto, I. Lum, E. Biro, D.R. Boomer, and Y. Zhou: Weld. J., 2003, vol. 82, pp. 307S-12S.

2. S. Lathabai, M.J. Painter, G.M.D. Cantin, and V.K. Tyagi: Scr. Mater., 2006, vol. 55, pp. 899-902.

3. Q. Yang, S. Mironov, Y.S. Sato, and K. Okamoto: Mater. Sci. Eng. A, 2010, vol. 527, pp. 4389-98.

4. H. Badarinarayan, F. Hunt, and K. Okamoto:Friction stir spot welding in Friction Stir Welding and Processing, R.S. Mishra and M.W. Mahoney, eds., ASM International, Ohio, 2007, pp. 235-72.

5. C. Schilling, and J. dos Santos: European patent EP 1230062 B1 (WO 2001/036144), May 17, 2006.

6. T. Rosendo, B. Parra, M.A.D. Tier, A.A.M. da Silva, J.F. dos Santos, T.R. Strohaecker, and N.G. Alcantara: Mater. Des., 2011, vol. 32, pp. 1094-1100.

7. G. Pieta, J. dos Santos, T.R. Strohaecker, and T. Clarke: Mater. Manuf. Process., 2013, vol. 29, pp. 934-40.

8. L.C. Campanelli, U.F.H. Suhuddin, A.I.S. Antonialli, J.F. dos Santos, N.G. Alcantara, and C. Bolfarini: J. Mater. Process. Technol., 2013, vol. 213, pp. 515-21.

9. M.D. Tier, T.S. Rosendo, J.F. dos Santos, N. Huber, J.A. Mazzaferro, C.P. Mazzaferro, and T.R. Strohaecker: J. Mater. Process. Technol., 2013, vol. 213, pp. 997-1005.

10. Y.Q. Zhao, H.J. Liu, Z. Lin, S.X. Chen, and J.C. Hou: Sci. Technol. Weld. Join, 2014, vol. 19, pp. 617-22.

11. U.F.H. Suhuddin, V. Fischer, and J.F. dos Santos: Scr. Mater., 2013, vol. 68, pp. 87-90.

12. J. Shen, U.F.H. Suhuddin, M.E.B. Cardillo, and J.F. dos Santos: Appl. Phys. Lett., 2014, vol. 104, p. 4.
13. J. Shen, M.E.B. Cardillo, and J.F.d. Santos: In 10th International Symposium on Friction Stir Welding, 2014 CD-ROM Beijing, P.R. China.

14. A.H. Plaine, A.R. Gonzalez, U.F.H. Suhuddin, J.F. dos Santos, and N.G. Alcantara: Mater. Des., 2015, vol. 83, pp. 36-41.

15. R.W. Fonda and K.E. Knipling: Sci. Technol. Weld. Join., 2011, vol. 16, pp. 288-94.

16. R.W. Fonda, J.F. Bingert, and K.J. Colligan: Scr. Mater., 2004, vol. 51 , pp. $243-48$.

17. D.P. Field, T.W. Nelson, Y. Hovanski, and K.V. Jata: Metall. Trans. A, 2001, vol. 32A, pp. 2869-77.

18. S.H.C. Park, Y.S. Sato, and H. Kokawa: Metall. Trans. A, 2003, vol. 34 A, pp. $987-94$.

19. J. Shen, F.F. Wang, U.F.H. Suhuddin, S.Y. Hu, W.Y. Li, and J.F. Dos Santos: Metall. Trans. A, 2015, vol. 46A, pp. 2809-13.

20. R.S. Mishra and Z.Y. Ma: Mater. Sci. Eng. R, 2005, vol. 50, pp. 1-78.

21. Y.S. Sato, F. Yamashita, Y. Sugiura, S.H.C. Park, and H. Kokawa: Scr. Mater., 2004, vol. 50, pp. 365-69.

22. K. Okayasu, H. Takekoshi, and H. Fukutomi: Mater. Trans., 2007, vol. 48, pp. 2002-07.

23. S. Li, I.J. Beyerlein, and M.A.M. Bourke: Mater. Sci. Eng. A, 2005, vol. 394, pp. 66-77.

24. G.R. Canova, U.F. Kocks, and J.J. Jonas: Acta Metall., 1984, vol. 32, pp. 211-26.

25. L.S. Toth, K.W. Neale, and J.J. Jonas: Acta Metall., 1989, vol. 37, pp. 2197-10.

26. R.W. Fonda and J.F. Bingert: Scr. Mater., 2007, vol. 57, pp. $1052-55$.

27. V.I. Elagin, V.V. Zakharov, and T.D. Rostova: Met. Sci. Heat Treat., 1992, vol. 34, pp. 37-45.

28. V.G. Davydov, T.D. Rostova, V.V. Zakharov, Y.A. Filatov, and V.I. Yelagin: Mater. Sci. Eng. A, 2000, vol. 280, pp. 30-36.

29. V.V. Zakharov: Met. Sci. Heat Treat., 2012, vol. 53, pp. 414-19.

30. P.B. Prangnell and C.P. Heason: Acta Metall., 2005, vol. 53, pp. 3179-92.

31. H.F. Huang, F. Jiang, J. Zhou, L.L. Wei, J.P. Qu, and L.L. Liu: $J$. Mater. Eng. Perform., 2015, vol. 24, pp. 4244-52.

32. P. Wagner, O. Engler, and K. Lucke: Textures Microstruct., 1991, vol. 14, pp. 927-32.

33. Y. Nakayama and K. Morii: Acta Metall., 1987, vol. 35, pp. 1747-55.

34. A. Duckham, R.D. Knutsen, and O. Engler: Acta Metall., 2001, vol. 49 , pp. $2739-49$.

35. F. Zhao, L. Wang, D. Fan, B.X. Bie, X.M. Zhou, T. Suo, Y.L. Li, M.W. Chen, C.L. Liu, M.L. Qi, M.H. Zhu, and S.N. Luo: Phys. Rev. Lett., 2016, vol. 116, p. 075501.

36. S.J. Lillywhite, P.B. Prangnell, and F.J. Humphreys: Mater. Sci. Technol., 2000, vol. 16, pp. 1112-20.

37. M.R. Drury and F.J. Humphreys: Acta Metall., 1986, vol. 34, pp. 2259-71. 